\title{
Erratum to: Safety Considerations of Inhaled Corticosteroids in the Elderly
}

\author{
Salvatore Battaglia $^{1}$ - Irene Cardillo ${ }^{1}$ Federico Lavorini ${ }^{2} \cdot$ \\ Mario Spatafora $^{1} \cdot$ Nicola Scichilone $^{1}$
}

Published online: 17 November 2015

(c) Springer International Publishing Switzerland 2015

\begin{abstract}
Inhaled corticosteroids (ICSs) are widely used in the treatment of patients with chronic obstructive pulmonary diseases. However, high-dose regimens and longterm use of ICSs have the potential to cause a variety of local and systemic side effects such as candidiasis, cataracts, glaucoma, and osteoporosis. The use of ICSs can also be associated with the risk of bone fractures, diabetes mellitus and pneumonia. These ICS-related side effects are of particular importance in elderly patients due to the presence of comorbidities and age-related behavioral, cognitive, and psychological problems, which can all interact with inhaled treatment. We reviewed the available literature on the clinically relevant side effects of ICSs in the elderly to provide practical measures to properly monitor and manage the risk of ICSs in the geriatric population. Inspection of the mouth, monitoring of ocular pressure, and use of bone-protective drugs may be necessary in patients on prolonged ICS therapy. Above all, the use of the lowest possible ICS dose and a careful re-assessment of the inhalation procedure should be recommended. Taken together, these observations suggest that physicians should use ICSs appropriately for those patients in whom the benefit will outweigh the risk, especially chronic obstructive pulmonary disease (COPD) patients with previous frequent exacerbations. Given the paucity of information on
\end{abstract}

The online version of the original article can be found under doi:10.1007/s40266-014-0213-1.

Nicola Scichilone

nicola.scichilone@unipa.it

1 Sezione di Pneumologia, Dipartimento di Biomedicina e Medicina Specialistica, University of Palermo, via Trabucco 180, 90146 Palermo, Italy

2 S.O.D. Pneumologia e Fisiopatologia, Azienda Ospedaliero Universitaria Careggi, Florence, Italy the topic and the need to extrapolate the results from studies with broader age ranges, we strongly encourage the design of specifically tailored clinical studies in the elderly.

\section{Erratum to: Drugs Aging (2014) 31:787-796 \\ DOI 10.1007/s40266-014-0213-1}

There are numerous errors in the citation of references in the original published article. The full article with all references corrected is re-published here.

\section{Key Points}

Asthma and chronic obstructive pulmonary disease (COPD) are inflammatory disorders of the airways. The pharmacological management of these chronic diseases is based on persistent and long-term use of inhaled corticosteroids (ICSs).

Asthma and COPD are among the most common chronic diseases in clinical settings, and physicians are expected to diagnose and manage those diseases in the geriatric population on a daily basis. The management of chronic obstructive respiratory diseases in the geriatric population is complicated by the increased occurrence of comorbidities and associated treatment, and by age-associated physiological and structural changes of the lung.

The chronic use of ICSs in the elderly is associated with the increased risk of local and systemic side effects such as candidiasis, cataract, glaucoma, diabetes mellitus, bone fractures, and pneumonia. Physicians should be aware of this in order to select those patients in whom the benefits will outweigh the risks. 


\section{Introduction}

Chronic obstructive respiratory diseases are amongst the most common non-communicable diseases in adults. Bronchial asthma is estimated to affect 300 million individuals worldwide, impairing quality of life and accounting for very high direct and indirect costs [1]; not infrequently, asthma is associated with near fatal or fatal attacks [1]. Evidence has accumulated to demonstrate that the prevalence of asthma in the most advanced ages is similar to that of younger ages [2]. Chronic obstructive pulmonary disease (COPD) is amongst the leading causes of morbidity and mortality [3], with the prevalence and burden of disease projected to increase in the coming decade due to persistent exposure to COPD risk factors and to the changing age structure of the world's population. Both diseases share a chronic inflammatory process of the airways, although the inflammatory cells that are specifically involved, and the response to treatment, are usually different. The frequent coexistence of comorbid conditions in older patients compared with younger subjects, together with age-associated changes of the human lung, may render the management of chronic obstructive diseases a complicated task.

The boundary line between the two diseases is undefined, particularly in a recently described condition named asthma/COPD overlap syndrome (ACOS) [4, 5]. The recognition of this nosological entity is complicated by the fact that the prevalence of ACOS increases with age [6]. Indeed, the pathologic and functional overlap between asthma and COPD has been estimated to be $<10 \%$ in individuals younger than 50 years and $>50 \%$ in patients aged 80 years or older [6].

Inhaled corticosteroids (ICSs) are considered the cornerstone in the treatment of asthma and COPD, alone or in combination with long-acting $\beta 2$-agonists (LABA). International GINA (Global Initiative for Asthma) guidelines for asthma recommend low-dose ICS for the mildest forms of the disease, and the addition of LABA to low dose ICS as first choice when symptoms are not controlled; medium or high doses of ICS are indicated for severe asthma [1]. In COPD, the global initiative for chronic obstructive lung disease (GOLD) guidelines encourage the use of ICS in the most severe stages (i.e., when lung function is impaired and subjects experience more severe respiratory symptoms and frequent exacerbations) [3]. The GINA guidelines [1] clearly state that asthma treatment in the elderly population is complicated by several factors, such as reduced coordination, declining sensory perception, and increased number of comorbidities and their associated symptoms and treatment. In the GOLD guidelines [3], adherence to therapy and careful monitoring of side effects are recommended. This undoubtedly applies to the subset of patients of advanced ages. Indeed, in both diseases, cognitive impairment, disability, loss of coordination in inhalation technique, need for persistent treatment, and polytherapy may affect the occurrence of side effects in the elderly.

We will herein address the question of the age-associated risk of ICS treatment in chronic obstructive respiratory diseases. Emphasis will be placed on practical measures that could be undertaken to offset the increased risk of complications from ICS in the elderly.

\section{Factors Influencing the Efficacy and Safety of Inhaled Corticosteroids (ICSs)}

\subsection{Pharmacokinetics and Pharmacodynamics of ICSs}

An ideal corticosteroid is effective and safe if it controls inflammation and has minor local and systemic effects. ICSs mainly used in asthma and COPD differ in terms of their pharmacokinetic and pharmacodynamics features, which in turn influence their efficacy and safety [7, 8]. ICSs act as topical agents. Indeed, the inhaled route of administration aims to exploit topical effect, directly near the site of deposition, minimizing the risk of systemic exposure and maximizing the anti-inflammatory effect [9].

The mechanism of action of corticosteroids is genomic and non-genomic. Both these actions have as a result an altered transcription of pro- and anti-inflammatory genes. The main pharmacokinetic/dynamic properties [9-11] depend on (a) receptor affinity [12]; (b) particle size and formulation [13, 14]; (c) oral, pulmonary, and systemic bioavailability [15-18]; (d) half-life [17]; (e) protein binding [19]; (f) bioactivation [17, 20]; (g) lipophilicity; (h) lipid conjugation [8]; and (i) metabolism [17].

Corticosteroid receptors (CR) are located along the entire airway epithelium and bronchial submucosa. Receptor affinity is the potency by which a corticosteroid binds its cytoplasmatic receptor. Receptor affinity is commonly expressed as relative receptor affinity (RRA) that consists of receptor affinity relative to the known standard dexamethasone. Therefore, the differences in RRA require a dose adjustment that reflects the differences in efficacy [1]. The amount of ICS reaching the lower airway depends on its particle size [7]. Particles with diameter $<5$ microns are likely deposited into bronchi and bronchioles, whereas particles with diameter $>5$ microns are more likely to deposit in the large airways. Particle size and distribution within the bronchial tree depend on ICS formulations [1]. Hydrofluoroalkane (HFA) formulations with extra-fine aerosols (e.g., beclomethasone, flunisolide, and 
ciclesonide) allow a higher distribution of the particles along the bronchial tree and deposition in the peripheral airways than non-extra-fine formulations, thus minimizing the deposition of the drug in the throat, and the consequent occurrence of local side effects, such as throat pain, dysphonia, reflex cough, pharyngitis, and candidiasis [21]. The bioavailability is the fraction of corticosteroid that reaches systemic circulation through various organs and can be responsible for systemic adverse effects. ICS in systemic circulation mainly originates from the amount deposited in the oropharynx, which is swallowed, and then adsorbed through the gastrointestinal tract. Moreover, a small fraction of the drug deposited in the lung can be adsorbed through the pulmonary vasculature [10]. The systemic effects are related to the hypothalamic-pituitary-adrenal (HPA) axis suppression and depend on dose, duration of treatment, and timing of corticosteroid administration [9, 10]. The bioavailability depends also on protein-binding properties. Protein binding, generally with albumin, is rapid and reversible, and minimizes systemic adverse effects, since only the free drug is pharmacologically active. Not all ICSs are administered in their active form; beclomethasone and ciclesonide must undergo a process of bioactivation. The lipophilicity of ICSs is the ability to dissolve into lipids. This characteristic positively influences the ICS passage across the phospholipidic cell membranes and is responsible for its distribution in the lipophilic tissues. Lung retention of ICS through this mechanism seems to be associated with prolonged half-life. Corticosteroids can be detected in the serum minutes after inhalation, and most of them have a short half-life $(<3 \mathrm{~h})$. Another mechanism by which lung retention can be prolonged is lipid conjugation. The addition of lipophilic side chains to an ICS increases its residence in the lung. The prolonged residence time from this 'pulmonary reservoir' of the drug allows for the once daily administration, minimizing the concentration of the free drug in the circulation, and therefore the risk of systemic effects. The amount of drug that is swallowed and absorbed in the bowel undergoes first pass metabolism through the liver, thus influencing the bioavailability. The liver is responsible for lower systemic side effects.

\subsection{Assessment of Risks and Benefits Associated with the Use of ICSs}

Despite the benefits associated with adding an ICS to a long-acting bronchodilator in the treatment of severe COPD, the use of ICSs in COPD is associated with a number of side effects, and the risk of these side effects may be increased by patient factors that are common in COPD, such as increasing age and multiple comorbid conditions. Arguably, the most serious side effect is the increased incidence of pneumonia, which has been observed among patients with COPD both in controlled clinical trials and case-control analyses. In a recent retrospective cohort analysis on patients diagnosed with COPD [22], the use of ICS was associated with an increase in the risk of pneumonia. The multivariate Cox regression also showed potentially dose-related increases in risk of pneumonia with adjusted HRs of 1.38, 1.69, and 2.57 for low-, moderate-, and high-ICS dose versus no ICS use. The risk was particularly evident in older patients and those with comorbid conditions. The assessment of the benefits and risks of adjunctive ICS treatment when making decisions regarding its use in elderly patients becomes, therefore, mandatory. Sobieraj and colleagues [23] conducted a metaanalysis to elucidate the benefits and risks associated with adjunctive ICS treatment in COPD. Three efficacy end points (exacerbations, mortality, and change in St. George's Respiratory Questionnaire [SGRQ] score), and two tolerability end points (pneumonia and oral candidiasis), together with study withdrawals, were evaluated in nine randomized clinical trials. The authors showed that the addition of an ICS to a LABA was associated with a reduced risk for exacerbations and improvement in healthrelated quality of life, but an increased risk for pneumonia (RR 1.68; $95 \%$ CI 1.28-2.21) and oral candidiasis (RR 2.93 ; $95 \%$ CI 1.94-4.42) compared with long-acting bronchodilator monotherapy. Taken together, these observations suggest that physicians should use ICS appropriately for those patients in whom the benefit will outweigh the risk, especially COPD patients with previous frequent exacerbations.

With regard to the risk of bone fractures associated with long-term use of ICS in the elderly population, the relative increase in fracture risk should be mostly weighted against the relative reduction of exacerbations in subjects with COPD. In a systematic review and meta-analysis on randomized and observational studies [24], the authors concluded that the benefit/harm ratio should be less of a concern for patients with low underlying fracture risk but who have more severe COPD and are experiencing frequent exacerbations. However, as cumulative ICS exposure may be hazardous in older patients with multiple comorbidities and low bone mineral density, bone-protective drugs may be warranted.

\section{Specific Considerations of ICSs in the Elderly}

Although the occurrence of systemic side effects of ICS is lower in comparison with those associated with the use of systemic corticosteroids, long-term use of high doses of ICS carries the risk of systemic side effects, such as cataract, glaucoma, diabetes, bone fractures, and pneumonia 
[25]. These ICS-related complications are more relevant in elderly patients, who are usually affected by several comorbidities with associated symptoms and therapy, which can interact with inhaled treatment.

\subsection{Candidiasis}

Oral, pharyngeal and even esophageal candidiasis are common adverse effects of ICS. However, little is known about the prevalence in the elderly. Residual ICS in the mouth could be influenced by various factors such as the patient's inhalation technique, patterns of inhalation, and peak inspiratory flow, all of which are variably impaired in elderly patients. In a retrospective study [26] using prescribed oral antifungal medication to estimate the presence of oral candidiasis in patients aged 65 years and over on ICS, the 3-year occurrence of oral candidiasis was $7 \%$. The occurrence was higher in users of pressurized metered dose inhalers (pMDIs) when compared with dry powder formulations (DPI) (6.9 versus $3.2 \%$, respectively; OR 2.2 ; $95 \%$ CI 1.8-2.8) and with high ICS doses compared with low doses $(6.4 \%$ versus 3.6, respectively; OR 1.8; $95 \%$ CI 1.6-2.1). Treatment factors associated with the first episode of oral candidiasis in new users of ICS were use of antibiotics, oral steroids, and anti-diabetics in conjunction with oral steroids.

\subsection{Cataract}

For systemic corticosteroids, the increased risk for the development of posterior subcapsular cataract is well established [27, 28]. Despite anecdotal reports [29, 30] suggesting an increased risk of cataracts also with the use of ICSs, studies specifically designed to investigate the association between ICS use and the risk of developing cataract failed to find significant relationships [31-33]. These studies were, however, of limited sample size and mostly conducted in children in whom cataract is a rare event. A cross-sectional study in elderly patients reported an increased risk of cataract associated with ICS use [34]. The sample size of this study was likely insufficient to evaluate the influence of daily ICS dosage and duration of treatment. In elderly patients with chronic obstructive respiratory diseases, Garbe et al. [35] investigated the association between the risk of cataract extraction and the use of ICS. The authors found that, independently of the dose employed, prolonged (more than 3 years) treatment with ICS was associated with elevated risk of cataract extractions. Of note, cataract extraction was more frequent in patients using a high $(>1 \mathrm{mg})$ average daily dose of beclomethasone dipropionate or budesonide for more than 2 years [35]. More recently, a meta-analysis [36] on two databases from UK and Canada on the use of ICS in adult and elderly patients concluded that the risk of cataracts increased by about $25 \%$ for each $1,000 \mu \mathrm{g}$ increase in daily dose of beclomethasone dipropionate or equivalent. Thus, although no firm link between cataract formation and ICS use has been made to date, the lowest possible ICS dose is recommended to minimize ocular complications [37].

\subsection{Glaucoma}

A prospective study of 187 patients with various pulmonary conditions and no documented history of glaucoma found no significant increase in intraocular pressure after the initiation of ICS therapy in these patients [38], suggesting that the risk of development of glaucoma with ICS therapy is low. Garbe et al. [39] conducted a case-control study involving more than 40,000 patients to investigate the association of ICS therapy with increased risk of ocular hypertension or open-angle glaucoma, and concluded that chronic use of ICS did not yield any increased risk of ocular damage. However, the authors suggested that monitoring of ocular pressure may be necessary in patients on prolonged ICS therapy.

\subsection{Diabetes}

The question of the association between ICS use and the induction (or worsening) of diabetes is a matter of debate, particularly in patients with COPD [40, 41]. Diabetes is a major cause of chronic disability and its prevalence increases steadily with age [40, 41]; both the prevalence and incidence of type 2 diabetes are higher in patients with COPD [42, 43]. Therefore, the co-existence of these two chronic conditions in the elderly becomes important when corticosteroid medications are to be used. Clinical trials in COPD did not report excess rates of adverse events of diabetes associated with use [44, 45]. However, these trials may not have had sufficient power to detect this excess risk [46]. An observational study conducted in the Veterans Affairs database found that ICS use was associated with a change in serum glucose concentration, in a dose-response manner, only in patients with diabetes [47]. Using a large (about 30,000) population-based cohort of asthma and COPD patients (mean age $65 \pm 15$ years), Suissa et al [46] found that ICS use was associated with a significant $34 \%$ increase in the risk of incident diabetes, defined as initiation of anti-diabetic medications. This risk increased with higher doses of ICS, with $1,000 \mu \mathrm{g}$ of fluticasone per day or equivalent associated with a $64 \%$ increase in risk. Moreover, in patients already treated for diabetes with oral hypoglycemic agents, the risk of progression to insulin also increased by $34 \%$ with the use of ICS, with the higher doses associated with a $54 \%$ increase [46]. A recent meta- 
analysis [48] evaluated double-blind, placebo-controlled trials involving budesonide or budesonide/formoterol in asthma and in COPD, and did not identify increased risk of new onset diabetes or hyperglycemia. However, the authors found that the risk for diabetes/hyperglycemia in budesonide-treated patients increased with increasing age. These findings should be interpreted with caution since the age range was very broad (patients $>4$ years of age were included).

\subsection{Bone Fractures}

Safety concerns, including osteoporosis and fractures, have been raised with regard to the long-term use of ICS [49]. Glucocorticoids reduce bone formation and increase bone reabsorption by direct actions on osteoblasts and osteoclasts. Corticosteroids may affect osteoporosis and fractures through two different mechanisms [50]. The mechanism of bone mineral density loss associated with chronic exposure to corticosteroids may be related to an increase in bone resorption at the cellular level [51]. In contrast, short-term corticosteroid effects on fractures may be related to an increase in apoptosis of osteocytes, increasing the risk for fractures as a result of short-term reduction in bone quality [52]. These phenomena can lead to loss of bone calcium, decreased vitamin D-mediated calcium absorption in the gut, decreased total body calcium stores, and hyperparathyroidism [53]. It is noteworthy that, particularly in women, reductions in production of sex hormones may further reduce bone mass. Studies investigating the association between ICS use and bone-mineral density in adults have given inconsistent results. Clinical studies have shown that accelerated bone re-absorption occurs at all doses $[54,55]$. In a study conducted to assess whether a dose-response relation between cumulative ICS dose and bone-mineral density exists, Wong and colleagues [81] calculated the cumulative dose of ICS in asthmatics and estimated its effect on bone density. The authors found a dose-response relationship between ICS use and mineral density. Although the study was performed in young individuals, in whom the effect is estimated to be modest, the clinical implications for elderly asthmatics may not be trivial, since these subjects will likely continue to be exposed to high doses of ICS over many years, thus increasing the risk of fracture. Indeed, fracture incidence, morbidity, and mortality rise significantly after the age of 70 years. Suissa et al. [56] conducted a case-control study nested within a population-based cohort of elderly individuals (mean age $80.7 \pm 6.25$ years) followed for at least 4 years. They found that long-term use of ICS at the usual recommended dose was not associated with a risk of fracture of the hip or upper extremities. There was, however, a small increase in overall fracture risk of $6 \%$ per
$1,000 \mu \mathrm{g}$ increase in mean daily dose, which was of borderline statistical significance. This increase was due entirely to an increase in the risk of an upper extremity fracture, which increased by $12 \%$ per each additional $1,000 \mu \mathrm{g}$ of ICS per day in beclomethasone-equivalent units. By analyzing data from two previous meta-analyses $[57,58]$, a very recent meta-review on adverse effects of ICS [25] concluded that ICS use was consistently associated with an increase in the risk of all types of fractures in patients with COPD, with an estimated number needed to treat for harm of 83 patients over 3 years of ICS use. Moreover, the dose-response relationship demonstrated that each $500 \mu \mathrm{g}$ increase in beclomethasone dose equivalents was associated with a $9 \%$ increase in risk of fractures, with modest overall effect size.

\subsection{Pneumonia}

A meta-analysis [59] on risk of pneumonia associated with long-term use of ICS in COPD showed a significantly increased risk of pneumonia (risk ratio of 1.57) with ICS. The effect was clearly demonstrated for inhaled fluticasone and mometasone. On the contrary, the evidence on whether budesonide is different from other ICSs in the risk of pneumonia remained inconclusive. The risk was evident, especially in the elderly and in those with more severe disease and lower lung function. However, in this metaanalysis data on elderly seems limited, because information only derives from a post-hoc analysis of the TORCH (TOwards a Revolution in COPD Health) trial [60]. In this trial, the hazard ratio for pneumonia increased from 1.62 for patients aged 55-64 years to 2.18 for patients aged $\geq 75$ years, in comparison with those $<55$ years. The above-cited meta-review on adverse effects of ICS [25] also re-analyzed available data for the risk of pneumonia, and pointed out that the number needed to treat for harm for pneumonia associated with ICS was estimated to be 60 patients per year. The lack of long-term head-to-head trials comparing fluticasone propionate, budesonide, and mometasone limited the possibility to find potential differences between these ICSs. In this regard, Suissa and coworkers [61] conducted a population-based cohort study of treated patients with COPD to assess whether the different ICSs vary in their risk of pneumonia. Although significant risk was seen with both fluticasone and budesonide, the rate ratio was higher with fluticasone (RR 2.01; $95 \%$ CI 1.93-2.10) than with budesonide (RR 1.17; $95 \%$ CI 1.09-1.26). The dose-response effect was particularly evident in the fluticasone group, where the risk of serious pneumonia increased from $46 \%$ with a low dose to $122 \%$ with a high dose [61]. Recent evidence from the PATHOS (An Investigation of the Past 10 Years Health Care for Primary Care Patients with Chronic Obstructive Pulmonary 
Fig. 1 Proposed factors influencing the choice of an inhaled corticosteroid (ICS) in elderly patients. The choice of a particular molecule of ICS should be based on its pharmacodynamic and pharmacokinetic profiles, and should also take into consideration the liver function of the patient (because of the first pass metabolism of most ICSs), patient adherence to once daily (OD) or twice daily (BID) administration, local and systemic side effects that can be accepted and tolerated, and coadministered drugs that can modify hepatic metabolism of ICS. Similarly, the choice of the device should be based on the cognitive state, visual capacity, muscular or skeletal diseases that could impair coordination and handgrip, and lung functional impairment

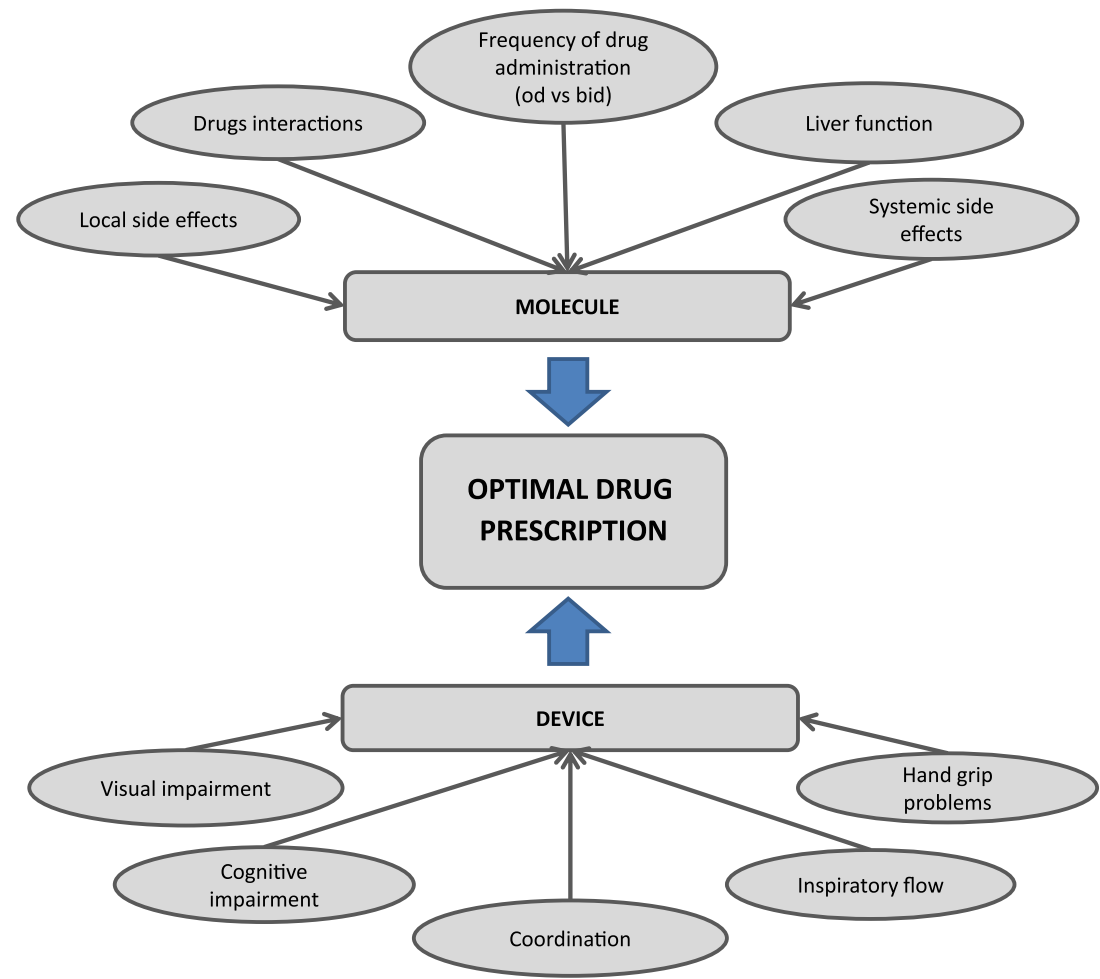

4 Practical Considerations for Elderly Patients on Long-Term Disease Management with ICS

In some countries, cost-sharing policies have been proposed to control growth in prescription drug costs. However, inflexible policies, such as prescription caps, high premiums, and deductibles, can lead to undesirable consequences. A Canadian study [65] provided information from a large-scale observation of a sequence of drug benefit policies in an older population ( $\geq 65$ years of age) over a 5-year period. It is possible to postulate that the shift from full coverage to fixed prescription drug copayment policy, and subsequently to income-based deductible plus $25 \%$ coinsurance policy, led to a financial incentive for patients to consider cost as a factor in their prescription decisions. As a consequence, income-based deductible policy coverage was associated with increased emergency hospitalization and physician visits in users of inhaled medications (corticosteroid, $\beta 2$-agonist, or anticholinergic) aged $\geq 65$ years with chronic obstructive pulmonary disease, asthma, or emphysema. Unfortunately, data divided by asthma or COPD were not presented, thus limiting the possibility to verify whether the observed effect of the policies is more evident in patients with asthma, where the role of ICS is well established.

Cognitive impairment increases with aging. About $17 \%$ of individuals with dementia reported association with COPD in the US Medicare database [66] and there is evidence that the occurrence of cognitive impairment is 
related to the effects of hypoxemia [67]. The reduced cognitive ability may obviously impact on the use of a device, which is a key factor for optimal control of chronic respiratory diseases. From this perspective, it is plausible to postulate that the observed additive effect on respiratoryrelated and all-cause hospitalizations and death in patients with COPD and coexisting cognitive impairment [68] is, at least in part, due to the difficulty in complying with prescribed therapy. Similarly, in asthma it has been demonstrated that optimal pharmacological treatment might improve some cognitive and instrumental activities in patients with Alzheimer's disease [69]. Elderly patients often experience difficulties in learning how to use pressurized metered dose or dry powder inhalers despite apparently normal cognitive functions and no obvious dyspraxia [70, 71]; this is perhaps due to unrecognized cognitive impairment and subclinical dyspraxia [70, 71], and supports a recommendation for the implementation of questionnaires in clinical practice, such as the Mini-Mental State Examination, to investigate global cognitive status when prescribing inhaler therapy for elderly patients [70].

Education and skills training are key issues for the successful long-term management of asthma [1] and COPD [3]. These include (but are not limited to) information, inhaler skills, adherence, written action plan, and, if applicable, self-monitoring. Individualized self-care education programs provided by a nurse are useful in older adults with moderate-to-severe asthma to enhance their self-care behaviors, manage their disease, and increase their quality of life, whereas computer-aided self-learning videos or asthma brochures seem inadequate substitutes in this age range [72]. A small study demonstrated the usefulness of assistance by caregivers during the inhalation procedure in elderly patients with asthma whose pulmonary function was not improved by self-administered ICS therapy [73]. A study [74] specifically aimed at assessing the inhalation technique by objectively measuring the ability to generate adequate peak inspiratory flow (PIF) for a variety of inhalers demonstrated that elderly patients with COPD, even when in stable clinical conditions, were generally unable to generate sufficient inspiratory flows for the activation of the dry powder inhaler. Moreover, as the effect of age on PIF reduction was independent of the disease severity [74], it is possible to hypothesize that elderly patients with asthma may also experience similar problems.

In asthma and COPD, patients aged $\geq 70$ years were demonstrated to show higher percentages of critical errors in the use of both MDIs and DPIs, compared with younger patients [75]. Allen [76] studied the threshold of cognitive impairment for the use of inhaler devices of increasing levels of complexity in patients aged $\geq 70$ years, and demonstrated that the more complex the device, the higher the threshold of cognitive function is required. The use of large volume spacers may have advantages over MDIs for elderly patients in terms of patient preference and inhaler technique [77]. However, another study [78] aimed at comparing MDIs with large volume spacers with breathactivated inhalers and DPIs in the elderly demonstrated that the latter were more likely to be used correctly than inhalers with large volume spacers. Despite some of the above-reported evidence and the generally accepted view that older people use conventional MDIs poorly, MDIs seem to be the most frequently employed type of inhaler
Fig. 2 Suggested strategies to minimize local and systemic adverse effects: for each condition, diagnostic procedures and therapeutic options are proposed. ICS inhaled corticosteroid

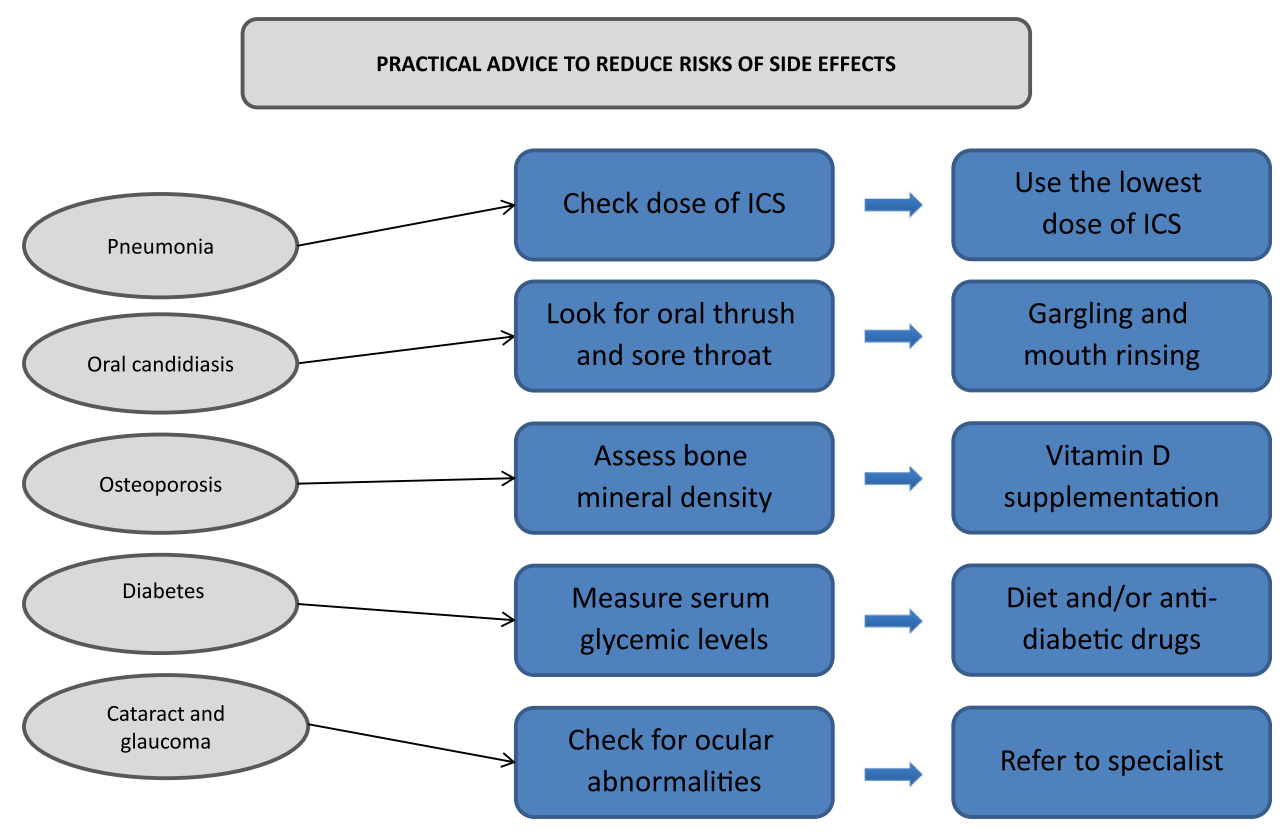


device amongst older people in the community, and are used adequately when in combination with large volume spacers [79]. However, this study excluded patients with cognitive impairment, likely underestimating the rate of failure to use inhalers properly in the community. Therefore, caution should be taken when prescribing an inhaler in older individuals, carefully re-assessing the inhalation procedure.

\section{Conclusions}

Figure 2 provides practical suggestions to evaluate, and properly manage, the adverse effects of ICSs. Knowledge of the significant and relevant risk factors associated with the development of oral candidiasis, such as ICS dose, device type, associated prescription/diseases or presence of dentures, can lead to early detection or prevention. In this regard, it has been demonstrated that gargling and mouth rinsing with about $20 \mathrm{ml}$ water for 5 seconds three times is sufficient to remove both the residual dry powder and aerosol-type ICS from the mouth [80]. The dose-response effect observed with ICSs with the incidence of serious pneumonia [61] has important practical considerations for elderly patients at high risk. In this respect, the use of the lowest effective dose of ICS, if any, is mandatory in the long-term management of stable COPD. Given the importance of the topic and the paucity of data, studies specifically designed to address this issue are strongly advocated.

Acknowledgments S Battaglia, I Cardillo, F Lavorini, M Spatafora, and $\mathrm{N}$ Scichilone declare no conflicts of interest related to this article.

Funding No sources of funding were used to support the writing of this manuscript.

\section{References}

1. Global Initiative for Asthma (GINA). Global strategy for asthma management and prevention. 2014. http://www.ginasthma.org/.

2. Scichilone N, Pedone C, Battaglia S, Sorino C, Bellia V. Diagnosis and management of asthma in the elderly. Eur J Intern Med. 2014;25:336-42.

3. Global Initiative for Chronic Obstructive Lung Disease (GOLD). Global strategy for the diagnosis, management and prevention of COPD. 2014. http://www.goldcopd.org/.

4. Louie S, Zeki AA, Schivo M, Chan AL, Yoneda KY, Avdalovic M, Morrissey BM, Albertson TE. The asthma-chronic obstructive pulmonary disease overlap syndrome: pharmacotherapeutic considerations. Expert Rev Clin Pharmacol. 2013;6:197-219.

5. Gibson PG, Simpson JL. The overlap syndrome of asthma and COPD: what are its features and how important is it? Thorax. 2009;64:728-35.

6. Soriano JB, Davis KJ, Coleman B, Visick G, Mannino D, Pride NB. The proportional Venn diagram of obstructive lung disease: two approximations from the United States and the United Kingdom. Chest. 2003;124:474-81.

7. Dalby C, Polanowski T, Larsson T, Borgstrom L, Edsbacker S, Harrison TW. The bioavailability and airway clearance of the steroid component of budesonide/formoterol and salmeterol/fluticasone after inhaled administration in patients with COPD and healthy subjects: a randomized controlled trial. Respir Res. 2009;10:104.

8. Miller-Larsson A, Jansson P, Runstrom A, Brattsand R. Prolonged airway activity and improved selectivity of budesonide possibly due to esterification. Am J Respir Crit Care Med. 2000;162:1455-61.

9. Colice GL. Pharmacodynamic and pharmacokinetic considerations in choosing an inhaled corticosteroid. Treat Respir Med. 2006;5:245-53.

10. Derendorf H, Nave R, Drollmann A, Cerasoli F, Wurst W. Relevance of pharmacokinetics and pharmacodynamics of inhaled corticosteroids to asthma. Eur Respir J. 2006;28:1042-50.

11. Barnes NC. The properties of inhaled corticosteroids: similarities and differences. Prim Care Respir J. 2007;16:149-54.

12. Valotis A, Neukam K, Elert O, Hogger P. Human receptor kinetics, tissue binding affinity, and stability of mometasone furoate. J Pharm Sci. 2004;93:1337-50.

13. Borgstrom $\mathrm{L}$. The pharmacokinetics of inhaled hydrofluoroalkane formulations. J Allergy Clin Immunol. 1999;104:S246-9.

14. Leach CL, Bethke TD, Boudreau RJ, Hasselquist BE, Drollmann A, Davidson P, Wurst W. Two-dimensional and three-dimensional imaging show ciclesonide has high lung deposition and peripheral distribution: a nonrandomized study in healthy volunteers. J Aerosol Med. 2006;19:117-26.

15. Richter K, Kanniess F, Biberger C, Nave R, Magnussen H. Comparison of the oropharyngeal deposition of inhaled ciclesonide and fluticasone propionate in patients with asthma. J Clin Pharmacol. 2005;45:146-52.

16. Affrime MB, Cuss F, Padhi D, Wirth M, Pai S, Clement RP, Lim J, Kantesaria B, Alton K, Cayen MN. Bioavailability and metabolism of mometasone furoate following administration by metered-dose and dry-powder inhalers in healthy human volunteers. J Clin Pharmacol. 2000;40:1227-36.

17. Kaliner MA. Pharmacologic characteristics and adrenal suppression with newer inhaled corticosteroids: A comparison of ciclesonide and fluticasone propionate. Clin Ther. 2006;28:319-31.

18. Harrison TW, Tattersfield AE. Plasma concentrations of fluticasone propionate and budesonide following inhalation from dry powder inhalers by healthy and asthmatic subjects. Thorax. 2003;58:258-60.

19. Rohatagi S, Luo Y, Shen L, Guo Z, Schemm C, Huang Y, Chen K, David M, Nave R, King SP. Protein binding and its potential for eliciting minimal systemic side effects with a novel inhaled corticosteroid, ciclesonide. Am J Ther. 2005;12:201-9.

20. Szefler S, Rohatagi S, Williams J, Lloyd M, Kundu S, Banerji D. Ciclesonide, a novel inhaled steroid, does not affect hypothalamic-pituitary-adrenal axis function in patients with moderate-tosevere persistent asthma. Chest. 2005;128:1104-14.

21. Roland NJ, Bhalla RK, Earis J. The local side effects of inhaled corticosteroids: current understanding and review of the literature. Chest. 2004;126:213-9.

22. Yawn BP, Li Y, Tian H, Zhang J, Arcona S, Kahler KH. Inhaled corticosteroid use in patients with chronic obstructive pulmonary disease and the risk of pneumonia: a retrospective claims data analysis. Int J Chron Obstruct Pulmon Dis. 2013;8:295-304.

23. Sobieraj DM, White CM, Coleman CI. Benefits and risks of adjunctive inhaled corticosteroids in chronic obstructive pulmonary disease: a meta-analysis. Clin Ther. 2008;30:1416-25.

24. Loke YK, Kwok CS, Singh S. Comparative cardiovascular effects of thiazolidinediones: systematic review and meta-analysis of observational studies. BMJ. 2011;342:d1309. 
25. Mattishent K, Thavarajah M, Blanco P, Gilbert D, Wilson AM, Loke YK. Meta-review: adverse effects of inhaled corticosteroids relevant to older patients. Drugs. 2014;74:539-47.

26. Kennedy WA, Laurier C, Gautrin D, Ghezzo H, Pare M, Malo JL, Contandriopoulos AP. Occurrence and risk factors of oral candidiasis treated with oral antifungals in seniors using inhaled steroids. J Clin Epidemiol. 2000;53:696-701.

27. Black RL, Oglesby RB, Von Sallmann L, Bunim JJ. Posterior subcapsular cataracts induced by corticosteroids in patients with rheumatoid arthritis. JAMA. 1960;174:166-71.

28. Urban RC Jr, Cotlier E. Corticosteroid-induced cataracts. Surv Ophthalmol. 1986;31:102-10.

29. Allen MB, Ray SG, Leitch AG, Dhillon B, Cullen B. Steroid aerosols and cataract formation. BMJ. 1989;299:432-3.

30. Karim AK, Thompson GM, Jacob TJ. Steroid aerosols and cataract formation. BMJ. 1989;299:918.

31. Abuekteish F, Kirkpatrick JN, Russell G. Posterior subcapsular cataract and inhaled corticosteroid therapy. Thorax. 1995;50:674-6.

32. Simons FE, Persaud MP, Gillespie CA, Cheang M, Shuckett EP. Absence of posterior subcapsular cataracts in young patients treated with inhaled glucocorticoids. Lancet. 1993;342:776-8.

33. Nassif E, Weinberger M, Sherman B, Brown K. Extrapulmonary effects of maintenance corticosteroid therapy with alternate-day prednisone and inhaled beclomethasone in children with chronic asthma. J Allergy Clin Immunol. 1987;80:518-29.

34. Cumming RG, Mitchell P, Leeder SR. Use of inhaled corticosteroids and the risk of cataracts. N Engl J Med. 1997;337:8-14.

35. Garbe E, Suissa S, LeLorier J. Association of inhaled corticosteroid use with cataract extraction in elderly patients. JAMA. 1998;280:539-43.

36. Weatherall M, Clay J, James K, Perrin K, Shirtcliffe P, Beasley R. Dose-response relationship of inhaled corticosteroids and cataracts: a systematic review and meta-analysis. Respirology. 2009;14:983-90.

37. Smeeth L, Boulis M, Hubbard R, Fletcher AE. A population based case-control study of cataract and inhaled corticosteroids. Br J Ophthalmol. 2003;87:1247-51.

38. Samiy N, Walton DS, Dreyer EB. Inhaled steroids: effect on intraocular pressure in patients without glaucoma. Can J Ophthalmol. 1996;31:120-3.

39. Garbe E, LeLorier J, Boivin JF, Suissa S. Inhaled and nasal glucocorticoids and the risks of ocular hypertension or open-angle glaucoma. JAMA. 1997;277:722-7.

40. Chapman KR, Mannino DM, Soriano JB, Vermeire PA, Buist AS, Thun MJ, Connell C, Jemal A, Lee TA, Miravitlles M, Aldington S, Beasley R. Epidemiology and costs of chronic obstructive pulmonary disease. Eur Respir J. 2006;27:188-207.

41. Yach D, Hawkes C, Gould CL, Hofman KJ. The global burden of chronic diseases: overcoming impediments to prevention and control. JAMA. 2004;291:2616-22.

42. Mannino DM, Thorn D, Swensen A, Holguin F. Prevalence and outcomes of diabetes, hypertension and cardiovascular disease in COPD. Eur Respir J. 2008;32:962-9.

43. Rana JS, Mittleman MA, Sheikh J, Hu FB, Manson JE, Colditz GA, Speizer FE, Barr RG, Camargo CA Jr. Chronic obstructive pulmonary disease, asthma, and risk of type 2 diabetes in women. Diabetes Care. 2004;27:2478-84.

44. Calverley PM, Anderson JA, Celli B, Ferguson GT, Jenkins C, Jones PW, Yates JC, Vestbo J, TORCH investigators. Salmeterol and fluticasone propionate and survival in chronic obstructive pulmonary disease. N Engl J Med. 2007;356:775-89.

45. Wedzicha JA, Calverley PM, Seemungal TA, Hagan G, Ansari Z, Stockley RA, Investigators I. The prevention of chronic obstructive pulmonary disease exacerbations by salmeterol/ fluticasone propionate or tiotropium bromide. Am J Respir Crit Care Med. 2008;177:19-26.

46. Suissa S, Kezouh A, Ernst P. Inhaled corticosteroids and the risks of diabetes onset and progression. Am J Med. 2010;123:1001-6.

47. Slatore CG, Bryson $\mathrm{CL}, \mathrm{Au} \mathrm{DH}$. The association of inhaled corticosteroid use with serum glucose concentration in a large cohort. Am J Med. 2009;122:472-8.

48. O'Byrne PM, Rennard S, Gerstein H, Radner F, Peterson S, Lindberg B, Carlsson LG, Sin DD. Risk of new onset diabetes mellitus in patients with asthma or COPD taking inhaled corticosteroids. Respir Med. 2012;106:1487-93.

49. Hanania NA, Chapman KR, Kesten S. Adverse effects of inhaled corticosteroids. Am J Med. 1995;98:196-208.

50. van Staa TP, Leufkens HG, Cooper C. The epidemiology of corticosteroid-induced osteoporosis: a meta-analysis. Osteoporos Int. 2002;13:777-87.

51. Weinstein RS, Jilka RL, Parfitt AM, Manolagas SC. Inhibition of osteoblastogenesis and promotion of apoptosis of osteoblasts and osteocytes by glucocorticoids. Potential mechanisms of their deleterious effects on bone. J Clin Invest. 1998;102:274-82.

52. Manolagas SC. Corticosteroids and fractures: a close encounter of the third cell kind. J Bone Miner Res. 2000;15:1001-5.

53. Lukert BP, Raisz LG. Glucocorticoid-induced osteoporosis: pathogenesis and management. Ann Intern Med. 1990;112:352-64.

54. Pouw EM, Prummel MF, Oosting H, Roos CM, Endert E. Beclomethasone inhalation decreases serum osteocalcin concentrations. BMJ. 1991;302:627-8.

55. Reid DM, Nicoll JJ, Smith MA, Higgins B, Tothill P, Nuki G. Corticosteroids and bone mass in asthma: comparisons with rheumatoid arthritis and polymyalgia rheumatica. Br Med J (Clin Res Ed). 1986;293:1463-6.

56. Suissa S, Baltzan M, Kremer R, Ernst P. Inhaled and nasal corticosteroid use and the risk of fracture. Am J Respir Crit Care Med. 2004;169:83-8.

57. Weatherall M, James K, Clay J, Perrin K, Masoli M, Wijesinghe $\mathrm{M}$, Beasley R. Dose-response relationship for risk of non-vertebral fracture with inhaled corticosteroids. Clin Exp Allergy. 2008:38:1451-8.

58. Loke YK, Cavallazzi R, Singh S. Risk of fractures with inhaled corticosteroids in COPD: systematic review and meta-analysis of randomised controlled trials and observational studies. Thorax. 2011;66:699-708.

59. Singh S, Loke YK. Risk of pneumonia associated with long-term use of inhaled corticosteroids in chronic obstructive pulmonary disease: a critical review and update. Curr Opin Pulm Med. 2010;16:118-22.

60. Crim C, Calverley PM, Anderson JA, Celli B, Ferguson GT, Jenkins C, Jones PW, Willits LR, Yates JC, Vestbo J. Pneumonia risk in COPD patients receiving inhaled corticosteroids alone or in combination: TORCH study results. Eur Respir J. 2009;34:641-7.

61. Suissa S, Patenaude V, Lapi F, Ernst P. Inhaled corticosteroids in COPD and the risk of serious pneumonia. Thorax. 2013;68:1029-36.

62. Janson C, Larsson K, Lisspers KH, Stallberg B, Stratelis G, Goike $\mathrm{H}$, Jorgensen L, Johansson G. Pneumonia and pneumonia related mortality in patients with COPD treated with fixed combinations of inhaled corticosteroid and long acting beta2 agonist: observational matched cohort study (PATHOS). BMJ. 2013;346:f3306.

63. Daveluy A, Raignoux C, Miremont-Salame G, Girodet PO, Moore N, Haramburu F, Molimard M. Drug interactions between inhaled corticosteroids and enzymatic inhibitors. Eur J Clin Pharmacol. 2009;65:743-5. 
64. Bolland MJ, Bagg W, Thomas MG, Lucas JA, Ticehurst R, Black PN. Cushing's syndrome due to interaction between inhaled corticosteroids and itraconazole. Ann Pharmacother. 2004;38:46-9.

65. Dormuth CR, Maclure M, Glynn RJ, Neumann P, Brookhart AM, Schneeweiss S. Emergency hospital admissions after incomebased deductibles and prescription copayments in older users of inhaled medications. Clin Ther. 2008;30 Spec No:1038-50.

66. Bynum JP, Rabins PV, Weller W, Niefeld M, Anderson GF, Wu AW. The relationship between a dementia diagnosis, chronic illness, medicare expenditures, and hospital use. J Am Geriatr Soc. 2004;52:187-94.

67. Thakur N, Blanc PD, Julian LJ, Yelin EH, Katz PP, Sidney S, Iribarren C, Eisner MD. COPD and cognitive impairment: the role of hypoxemia and oxygen therapy. Int J Chron Obstruct Pulmon Dis. 2010;5:263-9.

68. Chang SS, Chen S, McAvay GJ, Tinetti ME. Effect of coexisting chronic obstructive pulmonary disease and cognitive impairment on health outcomes in older adults. J Am Geriatr Soc. 2012;60:1839-46.

69. Bozek A, Jarzab J. Improved activity and mental function related to proper antiasthmatic treatment in elderly patients with Alzheimer's disease. Allergy Asthma Proc. 2011;32:341-5.

70. Allen SC, Ragab S. Ability to learn inhaler technique in relation to cognitive scores and tests of praxis in old age. Postgrad Med J. 2002;78:37-9.

71. Allen SC, Jain M, Ragab S, Malik N. Acquisition and short-term retention of inhaler techniques require intact executive function in elderly subjects. Age Ageing. 2003;32:299-302.

72. Huang $\mathrm{TT}, \mathrm{Li} \mathrm{YT}$, Wang $\mathrm{CH}$. Individualized programme to promote self-care among older adults with asthma: randomized controlled trial. J Adv Nurs. 2009;65:348-58.
73. Matsunaga K, Yamagata T, Minakata Y, Ichinose M. Importance of assistance by caregivers for inhaled corticosteroid therapy in elderly patients with asthma. J Am Geriatr Soc. 2006;54:1626-7.

74. Jarvis S, Ind PW, Shiner RJ. Inhaled therapy in elderly COPD patients; time for re-evaluation? Age Ageing. 2007;36:213-8.

75. Melani AS, Zanchetta D, Barbato N, Sestini P, Cinti C, Canessa PA, Aiolfi S, Neri M. Inhalation technique and variables associated with misuse of conventional metered-dose inhalers and newer dry powder inhalers in experienced adults. Ann Allergy Asthma Immunol. 2004;93:439-46.

76. Allen SC. Competence thresholds for the use of inhalers in people with dementia. Age Ageing. 1997;26:83-6.

77. Connolly MJ. Inhaler technique of elderly patients: comparison of metered-dose inhalers and large volume spacer devices. Age Ageing. 1995;24:190-2.

78. Jones V, Fernandez C, Diggory P. A comparison of large volume spacer, breath-activated and dry powder inhalers in older people. Age Ageing. 1999;28:481-4.

79. Ho SF, OMahony MS, Steward JA, Breay P, Burr ML. Inhaler technique in older people in the community. Age Ageing. 2004;33:185-8.

80. Ohbayashi $\mathrm{H}$, Adachi $\mathrm{M}$. Influence of dentures on residual inhaled corticosteroids in the mouths of elderly asthma patients. Respir Investig. 2012;50:54-61.

81. Wong CA, Walsh LJ, Smith CJ, Wisniewski AF, Lewis SA, Hubbard R, Cawte S, Green DJ, Pringle M, Tattersfield AE. Inhaled corticosteroid use and bone-mineral density in patients with asthma. Lancet. 2000;355:1399-403. 